\title{
2688. Effect of vibration in the treatment of children with spastic diplegic cerebral palsy
}

\author{
Vilma Dudoniene ${ }^{1}$, Egle Lendraitiene ${ }^{2}$, Jurate Pozeriene ${ }^{3}$ \\ ${ }^{1,3}$ Lithuanian Sports University, Sporto g. 6, LT-44221, Kaunas, Lithuania \\ ${ }^{2}$ Lithuanian University of Health Sciences, Eiveniu g. 2, LT-50009, Kaunas, Lithuania \\ ${ }^{1}$ Corresponding author \\ E-mail: ${ }^{1}$ vilma.dudoniene@lsu.lt, ${ }^{2} e g l e \_77 @ y a h o o . c o m,{ }^{3}$ jurate.pozeriene@lsu.lt \\ Received 14 February 2017; received in revised form 13 June 2017; accepted 22 June 2017
}

DOI https://doi.org/10.21595/jve.2017.18250

Check for updates

Abstract. Cerebral palsy is one of the leading causes of movement and posture disorders. Recently, Vibration, as a treatment method in clinical practice has been used as a complementary approach. The aim of this intervention was to determine the effect of vibration in addition to conventional therapy on spasticity, range of motion and gross motor functions in children with cerebral palsy. A total of 20 children with spastic diplegic cerebral palsy (7-10 years old) were randomly divided into two equal groups (conventional therapy - Control group, and conventional therapy plus Vibration - Vibration group), and participated in a 3-week physiotherapy program. The same exercise program was prescribed for children of both groups; frequency of intervention - five times a week, one session lasted for $45 \mathrm{~min}$. Children in the vibration group apart from conventional therapy also received treatment on a special vibration equipment set at $15 \mathrm{~Hz}$ frequency. Ashwort scale was used to assess spasticity, goniometry - range of motion, and Gross Motor Function Measure (GMFM) 88 domain - to assess standing (D) and mobility (E - walking, jumping, and running) functions. Both interventions significantly increased range of motion, decreased spasticity in legs and improved standing and mobility functions $(p<0.05)$. No statistical differences were found between the two groups after interventions.

Keywords: vibration therapy, cerebral palsy, spasticity, motor functions.

\section{Introduction}

Cerebral palsy (CP) is one of the leading causes of movement and posture disorders, which occurs with 2-3 of every 1000 individuals [1]. The majority of people with CP have the spastic syndrome of which the diplegic group is the smallest [2].

Spastic diplegic cerebral palsy usually affects muscle control and coordination, and affected people have increased muscle tone which leads to tight muscles and exaggerated reflexes. Leg muscles tend to be extremely tight [3]. So, the main treatment goal is to reduce stiffness in joints and increase the range of motion.

Various methods such as Vojta, Hippotherapy, Hydrotherapy, Massage, Casting and others are applied to children with cerebral palsy to manage spasticity and contractures, to improve muscle strength, motor activities, functions and self-care [3]. Recently a rising interest in the use of vibration for achieving therapeutic or physical performance goals has been observed [4-8].

Most authors hypothesize that vibrations stimulate muscle spindles and alpha-motoneurons, which initiate a muscle contraction. An immediate effect of a non-exhausting vibration session is an increase in muscle power. Scientific findings suggest that vibration could represent an effective exercise intervention for enhancing neuromuscular performance [9]. The frequency of vibration devices typically ranges from a few $\mathrm{Hz}$ to $50 \mathrm{~Hz}$, with amplitudes ranging from a few micrometers to several millimetres, and entire session takes from 5 to 20 minutes [5]. The findings of researchers suggest that whole body vibration may improve mobility in children with cerebral palsy through a positive effect on the leg muscles [8]. Some authors found out that whole body vibration is safe and can be used in children with $\mathrm{CP}$, as it is usually well tolerated by children with cerebral palsy and may improve standing function $[5,7,10]$. The research in adults with $\mathrm{CP}$ suggests that whole body vibration has no negative effect on spasticity [11]. 
Therefore, the aim in this clinical intervention was to compare the effect of conventional therapy and vibration in addition to conventional therapy in patients with spastic diplegic cerebral palsy in terms of spasticity, range of motion and standing, as well as mobility functions of Gross Motor Function Measure.

\section{Methods}

\subsection{Participants}

The subjects were recruited from a sanatorium, inpatient rehabilitation department, specialized in the treatment of children with cerebral palsy. The study included 20 children: 11 boys and 9 girls who were diagnosed with spastic diplegic cerebral palsy. The subjects were randomly divided into two groups: Control ( $n=10 ; 5$ boys and 5 girls; mean age $8.70 \pm 0.90$ yr.), and Vibration ( $n=10 ; 6$ boys and 4 girls, mean age $8.56 \pm 1.07$ yr.). The inclusion criteria were: age between 7 and 10 years, written consent of parents letting their child to participate in the study. Patients were ineligible for study participation if they had a history of recent surgery (at least one year post orthopaedic surgery), mental disorder, history of epilepsy, hearing problems, history of recent botulinum toxin treatment (at least 6 months post injections).

\section{Intervention}

All subjects participated in a 3-week (14 procedures, 45 minute sessions every working day) physiotherapy program. The conventional physiotherapy program consisted of stretching (Achilles tendon, hamstrings, hip flexors and extensors, abdominals), muscle strengthening (spine extensors, lower abdominals, hip and knee extensors, ankle dorsiflexes) and balance training exercises with Swiss balls, balance pads, and sticks. Each exercise was repeated 7-10 times within 2-3 sessions.

In addition to the conventional physiotherapy program, participants in Vibration group received vibration on a commercially available device (Swing Massager - HM01-08YA, China) with a side-alternating vibration along the sagittal axis (Fig. 1).

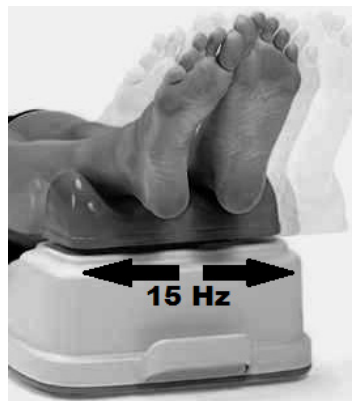

Fig. 1. Position of the legs during vibration

In this study, the device was set to produce a peak to peak-sinusoidal vibration with the amplitude ranging from 2 to $6 \mathrm{~mm}$. There were three positions illustrated on the device marked as ' 1 ', ' 2 ', and ' 3 ' corresponding to peak-to-peak displacements of $2 \mathrm{~mm}, 4 \mathrm{~mm}$, and $6 \mathrm{~mm}$ and four sets of duration: 5, 10, 15 and 20 min. During vibration, the patient had to lie on a couch with their legs put on the massager. The frequency used in this study was $15 \mathrm{~Hz}$. At the beginning of intervention vibration duration was $5 \mathrm{~min}$ (plus $40 \mathrm{~min}$ of exercise), after 7 procedures $-10 \mathrm{~min}$. (and $35 \mathrm{~min}$. of exercise). Before applying vibration, vibration tolerance test was done. The protocol of both interventions is presented in Table 1.

The study was approved by the Institutional Ethics Committee. Informed consent was obtained from parents or the legal guardians of all children. 
Table 1. Vibration protocol

\begin{tabular}{|c|c|c|c|}
\hline Procedures & Peak-to-peak displacement & Frequency & Duration of vibration \\
\hline 1st & $2 \mathrm{~mm}$ & $15 \mathrm{~Hz}$ & $5 \mathrm{~min}$ \\
\hline 2nd & $2 \mathrm{~mm}$ & $15 \mathrm{~Hz}$ & $5 \mathrm{~min}$ \\
\hline 3rd & $2 \mathrm{~mm}$ & $15 \mathrm{~Hz}$ & $5 \mathrm{~min}$ \\
\hline 4th & $2 \mathrm{~mm}$ & $15 \mathrm{~Hz}$ & $5 \mathrm{~min}$ \\
\hline 5th & $2 \mathrm{~mm}$ & $15 \mathrm{~Hz}$ & $5 \mathrm{~min}$ \\
\hline 6th & $4 \mathrm{~mm}$ & $15 \mathrm{~Hz}$ & $5 \mathrm{~min}$ \\
\hline 7th & $4 \mathrm{~mm}$ & $15 \mathrm{~Hz}$ & $10 \mathrm{~min}$ \\
\hline 8th & $4 \mathrm{~mm}$ & $15 \mathrm{~Hz}$ & $10 \mathrm{~min}$ \\
\hline 9th & $4 \mathrm{~mm}$ & $15 \mathrm{~Hz}$ & $10 \mathrm{~min}$ \\
\hline 10th & $4 \mathrm{~mm}$ & $15 \mathrm{~Hz}$ & $10 \mathrm{~min}$ \\
\hline 11th & $6 \mathrm{~mm}$ & $15 \mathrm{~Hz}$ & $10 \mathrm{~min}$ \\
\hline 12th & $6 \mathrm{~mm}$ & $15 \mathrm{~Hz}$ & $10 \mathrm{~min}$ \\
\hline 13th & $6 \mathrm{~mm}$ & $15 \mathrm{~Hz}$ & $10 \mathrm{~min}$ \\
\hline 14th & $6 \mathrm{~mm}$ & $15 \mathrm{~Hz}$ & $10 \mathrm{~min}$ \\
\hline
\end{tabular}

\section{Outcome measures}

Range of motion (ROM) [12]. ROM of hip flexion and extension, ankle dorsal and plantar flexion were measured. The purpose of these measurements was to assess spasticity-related changes in ROM.

Spasticity of knee extensors was evaluated applying the Modified Ashwort scale (MAS) [13]. This scale grades the level of resistance to passive movement. The MAS has 6 degrees $(0,1,2,3,4$, and 5$)$.

Gross motor functions were measured with GMFM-88 [14]. It consists of 88 items within 5 dimensions: (A) lying and rolling; (B) sitting; (C) crawling and kneeling; (D) standing; (E) walking, running and jumping. The items are scored using a 4-point scale $(0-$ does not initiate task; 1 - initiates task $(<10 \%) ; 2$ - partially completes task $(10-99 \%) ; 3$ - completes task $(100 \%)$ and the scores are presented in percentages. Dimensions D and E were assessed in this study.

All measures were performed at a baseline and after the 3-week intervention.

\section{Statistical analysis}

The statistical analyses were performed using statistical package for social sciences (SPSS) version 20. Descriptive statistics (mean and standard deviation) were computed for all data. Wilcoxon's signed rank test was used to analyse differences before and after intervention, and Mann-Whitney $U$ test - to analyse differences between the two groups. The difference across the groups and trials were considered statistically significant when $P$ value was less than 0.05 . As all subjects completed interventions, no adjustments were needed for drop-outs. No power analysis was undertaken for the present study.

\subsection{Results}

The study included twenty children with spastic diplegic cerebral palsy. The results of range of motion analysis are summarised in Table 2. There were no statistical differences in the pre-intervention range of motion between two randomly assigned groups. Both interventions statistically significantly improved range of motion, but there were no significant differences between groups after interventions $(p>0.05)$.

Analysis of muscle spasticity measurements revealed that too high muscle tone before intervention decreased significantly after both interventions (Table 3), and gross motor functions (Table 4) improved significantly, but there were no significant differences between groups before and after interventions $(p>0.05)$. 
Table 2. Range of motion measures before and after interventions

\begin{tabular}{|c|c|c|c|c|}
\hline \multirow{2}{*}{ Range of motion (degrees) } & \multicolumn{2}{|c|}{ Control group } & \multicolumn{2}{c|}{ Vibration group } \\
\cline { 2 - 5 } & Before & After & Before & After \\
\hline Hip flexion (R) & $104.3 \pm 5.94$ & $107.3 \pm 6.01^{*}$ & $104.1 \pm 5.77$ & $111.3 \pm 5.43^{*}$ \\
\hline Hip flexion (L) & $105.9 \pm 6.63$ & $111.7 \pm 5.76^{*}$ & $105.8 \pm 6.60$ & $113.5 \pm 5.08^{*}$ \\
\hline Hip extension (R) & $4.7 \pm 1.23$ & $6.5 \pm 1.07^{*}$ & $4.7 \pm 1.16$ & $6.4 \pm 0.97^{*}$ \\
\hline Hip extension (L) & $5.7 \pm 0.89$ & $6.9 \pm 0.72^{*}$ & $5.2 \pm 1.04$ & $7.1 \pm 1.01^{*}$ \\
\hline Foot dorsiflexion (R) & $6.3 \pm 1.11$ & $7.6 \pm 1.19^{*}$ & $6.3 \pm 0.89$ & $8.0 \pm 0.91^{*}$ \\
\hline Foot dorsiflexion (L) & $8.9 \pm 2.37$ & $11.2 \pm 2.28^{*}$ & $8.3 \pm 2.23$ & $10.6 \pm 2.13^{*}$ \\
\hline Foot plantar flexion (R) & $14.2 \pm 1.03$ & $15.8 \pm 1.09^{*}$ & $14.3 \pm 1.29$ & $15.8 \pm 1.13^{*}$ \\
\hline Foot plantar flexion (L) & $14.5 \pm 0.81$ & $16.0 \pm 1.07^{*}$ & $15.0 \pm 1.24$ & $16.5 \pm 1.39^{*}$ \\
\hline$* p<0.05$, within groups, R - right; L - left \\
\hline
\end{tabular}

Table 3. Changes in spasticity before and after interventions

\begin{tabular}{|c|c|c|c|c|}
\hline \multirow{2}{*}{ Muscle Spasticity (points) } & \multicolumn{2}{|c|}{ Control group } & \multicolumn{2}{c|}{ Vibration group } \\
\cline { 2 - 5 } & Before & After & Before & After \\
\hline Right knee extensors & $3.5 \pm 0.29$ & $2.2 \pm 0.21^{*}$ & $3.3 \pm 0.34$ & $2.1 \pm 0.4^{*}$ \\
\hline Left knee extensors & $2.4 \pm 0.43$ & $1.9 \pm 0.59^{*}$ & $2.3 \pm 0.46$ & $1.5 \pm 0.43^{*}$ \\
\hline$* p<0.05$, within groups
\end{tabular}

Table 4. Gross motor function measure (GMFM) dimensions D (standing) and $\mathrm{E}$ (walking, running, jumping - mobility) before and after interventions

\begin{tabular}{|c|c|c|c|c|}
\hline \multirow{2}{*}{ Gross motor functions (\%) } & \multicolumn{2}{|c|}{ Control group } & \multicolumn{2}{c|}{ Vibration group } \\
\cline { 2 - 5 } & Before & After & Before & After \\
\hline Standing & $21.5 \pm 4.95$ & $27.4 \pm 5.19^{*}$ & $15.4 \pm 4.99$ & $22.1 \pm 5.26^{*}$ \\
\hline Mobility & $32.5 \pm 7.96$ & $41.1 \pm 7.81^{*}$ & $32.1 \pm 9.81$ & $42.5 \pm 11.83^{*}$ \\
\hline$* p<0.05$, within groups
\end{tabular}

\section{Discussion}

The aim of this study was to compare changes in ROM, spasticity and motor functions after 3-week intervention applying conventional physiotherapy and vibration in addition to conventional physiotherapy. There has been limited research on the effect of vibration in the treatment of children with spastic diplegic cerebral palsy, although numerous studies have confirmed the beneficial effects of whole body vibration exercise on the musculoskeletal system $[4,15,16]$, and mobility $[7,8]$.

In the present study, the results reveal significant improvement in ROM, spasticity and gross motor functions after both interventions. Spasticity is considered to be a primary limiting impairment in children with spastic diplegic CP and the goal in any treatment programme is to improve both passive and active movements. Significant reduction of spasticity in legs let children from both groups to perform leg movements in higher amplitude $(p<0.05)$. Hence, increase in ROM and reduction of spasticity improved standing and mobility functions in all children significantly, but there were no significant differences between groups after two different interventions $(p>0.05)$.

Ibrahim et al. conducted a study in which subjects - children with spastic diplegic cerebral palsy were divided into two groups: the whole body vibration group received conventional physiotherapy and vibration, and the control group received only the conventional physiotherapy. After 12 weeks of interventions spasticity decreased and motor functions improved in both groups, but significant difference between groups was found in $6 \mathrm{~min}$. walk test and GMFM E dimension (walking, running, jumping - mobility) with better results $(p<0.05)$ in WHV group [15].

Ruck et al. have demonstrated that vibration therapy is safe and has some effect on mobility in children with cerebral palsy, but there still is a need of standardized methods [7]. Researchers $[6-8,15,17,18]$ examine effect of WBV with different frequencies for balance and gait training, 
for speed, balance, and proprioception, ROM and functional activities (Table 5.).

In majority of studies analysing the effect of vibration, whole body vibration device was used when a patient had to stand in a vertical body position on a vibration plate. In our case we used a different device where a child had to lay down with their legs on the device. We found only one study analysing the effect of vibroacoustic therapy in the treatment of children with cerebral palsy where children were in a lying position during intervention. Katusic et al. found that intervention which lasted for 12 weeks was effective using vibroacoustic bed pad with treatment duration of $20 \mathrm{~min}$. twice a week and frequency of $40 \mathrm{~Hz}$ [19].

This study has a number of limitations. The most important limitation is a short duration of intervention, as we investigated patients who came to rehabilitation only for three weeks from different regions of the country. The shortest vibration intervention mentioned in the scientific literature was 5 weeks [20]. Another limitation is a small number of participants. We assume that vibration interventions have a great potential in a therapeutic context, since they are well tolerated by children with spastic diplegia. Further studies with longer duration and follow-up assessment are needed to investigate the effect of vibration in the treatment programmes to improve clinical benefits.

Table 5. Characteristics of studies that have been performed to examine WBV effect

\begin{tabular}{|c|c|c|c|c|c|}
\hline & $\begin{array}{c}\text { Participants } \\
\text { ( } n \text {; control, vibro) }\end{array}$ & Age & Duration of vibration & $\begin{array}{c}\text { Frequency of } \\
\text { vibration }\end{array}$ & $\begin{array}{l}\text { Duration of } \\
\text { intervention }\end{array}$ \\
\hline $\begin{array}{l}\text { Ruck et } \\
\text { al., } 2010\end{array}$ & $7 / 10$ & $6-12$ years & $\begin{aligned} & 3 \mathrm{sessions} \times 3 \mathrm{~min} \\
&= 9 \mathrm{~min} / \mathrm{per} \text { school day } \\
&\end{aligned}$ & $12-18 \mathrm{~Hz}$ & 6 months \\
\hline $\begin{array}{l}\text { Lee \& } \\
\text { Chon, } \\
2013\end{array}$ & $15 / 15$ & $10 \pm 2.26$ & $\begin{array}{l}6 \text { sessions } \times 3 \mathrm{~min} \\
\quad=18 \mathrm{~min}\end{array}$ & $\begin{array}{c}3 \mathrm{~min}-5-8 \mathrm{~Hz} \\
3 \mathrm{~min}-10-15 \mathrm{~Hz} \\
3 \mathrm{~min}-15-20 \mathrm{~Hz} \\
3 \mathrm{~min}-20-25 \mathrm{~Hz} \\
3 \mathrm{~min}-15-20 \mathrm{~Hz} \\
3 \mathrm{~min}-10-15 \mathrm{~Hz}\end{array}$ & 8 weeks \\
\hline $\begin{array}{c}\text { Ibrahim et } \\
\text { al., } 2014\end{array}$ & $15 / 15$ & $\begin{array}{l}8-12 \text { years } \\
9.63 \pm 1.41\end{array}$ & $\begin{array}{c}3 \text { sessions } \times 3 \mathrm{~min} \\
=9 \mathrm{~min}\end{array}$ & $12-18 \mathrm{~Hz}$ & 12 weeks \\
\hline $\begin{array}{l}\text { Wren et } \\
\text { al., } 2010\end{array}$ & $0 / 31$ & $6-12$ years & $10 \mathrm{~min} /$ day & $30 \mathrm{~Hz}$ & 6 months \\
\hline $\begin{array}{c}\text { Stark et } \\
\text { al., } 2010\end{array}$ & $0 / 78$ & $2-24$ & $\begin{array}{c}3 \text { sessions } \times 3 \mathrm{~min} \\
=9 \mathrm{~min} / \text { daily }\end{array}$ & $5-25 \mathrm{~Hz}$ & 3 months \\
\hline $\begin{array}{c}\text { Tupimai } \\
\text { et al., } \\
2016 \\
\end{array}$ & 12 & $10.6 \pm 2.4$ & $\begin{array}{l}1 \mathrm{~min} \text { vibro } 1 \text { rest } \\
10 \mathrm{~min} / \text { workday }\end{array}$ & $20 \mathrm{~Hz}$ & 6 weeks \\
\hline
\end{tabular}

\section{Conclusion}

The results of the present study showed that 3-week intervention of vibration in addition to conventional therapy and conventional therapy only, significantly increased range of motion, decreased spasticity in legs and improved standing and mobility functions in children with spastic diplegic cerebral palsy. There were no significant differences between the two groups after interventions in terms of spasticity, range of motion and standing, as well as mobility functions of Gross Motor Function Measure. A 3-week intervention, using vibration on a commercially available Swing Massager, is too short time to achieve clinical benefit.

\section{Acknowledgements}

We would like to express our sincere gratitude to all subjects and their families for their willing participation and co-operation in this study. 


\section{References}

[1] Koman L. A., Smith B. P., Shilt J. S. Cerebral palsy. Lancet, Vol. 363, Issue 9421, 2004, p. 1619-1631.

[2] Odding E., Roebroeck M. E., Stam H. J. The epidemiology of cerebral palsy: incidence, impairments and risk factors. Disability and Rehabilitation, Vol. 28, Issue 4, 2006, p. 183-191.

[3] Elshafey M. A., Abd-Elaziem A., Gouda R E. Functional stretching exercise submitted for spastic diplegic children: a randomized control study. Rehabilitation Research and Practice, Vol. 2014, 2014.

[4] Novak I., et al. A systematic review of interventions for children with cerebral palsy: state of the evidence. Developmental Medicine and Child Neurology. Vol. 55, Issue 10, 2013, p. 885-910.

[5] Rauch F. Vibration therapy. Disability and Rehabilitation, Vol. 51, Issue 4, 2009, p. 166-168.

[6] Stark C., et al. Effect of a new physiotherapy concept on bone mineral density, muscle force and gross motor function in children with bilateral cerebral palsy. Journal of Neuronal and Musculoskeletal Interactions, Vol. 10, Issue 2, 2010, p. 151-158.

[7] Ruck J., Chabot G., Rauch F. Vibration treatment in cerebral palsy: A randomized controlled pilot study. Journal of Neuronal and Musculoskeletal Interactions, Vol. 10, Issue 1, 2010, p. 77-83.

[8] Lee B. K., Chon S. C. Effect of whole body vibration training on mobility in children with cerebral palsy: a randomized controlled experimenter-blinded study. Clinical Rehabilitation, Vol. 27, Issue 7, 2013, p. 599-607.

[9] Cardinal M., Bosco C. The use of vibration as exercise intervention. Exercise and Sport Sciences Reviews, Vol. 31, Issue 1, 2003, p. 3-7.

[10] Saquetto M., et al. The effects of whole body vibration on mobility and balance in children with cerebral palsy: a systematic review with meta-analysis. Journal of Musculoskeletal and Neuronal Interactions, Vol. 15, Issue 2, 2015, p. 137-144.

[11] Ahlborg L., Andersson Ch., Julin P. Whole-body vibration training compared with resistance training: effect on spastocoty, muscle strength and motor performance in adults with ceebral palsy. Journal of Rehabilitation Medicine, Vol. 38, Issue 5, 2006, p. 302-308.

[12] Norkin C. C., White D. J. Measurement of Joint Motion: a Guide to Goniometry. 5th Edition, FA Davis Company, Philadelphia, 2016.

[13] Dursun N., et al. A randomized controlled trial on effectiveness of intermittent serial casting on spastic equinus foot in children with cerebral palsy after botulinum toxin-a treatment. American Journal of Physical Medicine and Rehabilitation, 2016.

[14] Aloitabi M., et al. The efficacy of GMFM-88 and GMFM-66 to detect changes in gross motor function in children with cerebral palsy (CP): a literature review. Disability and Rehabilitation, Vol. 36, Issue 8, 2014, p. 617-627.

[15] Ibrahim M. M., Eid M., Moawd S. A. Effect of whole-body vibration on muscle strength, spasticity, and motor performance in spastic diplegic cerebral palsy children. The Egyptian Journal of Medical Human Genetics, Vol. 15, 2014, p. 173-179.

[16] Aye Th., Thein S., Hlaing Th. Effects of strength training program on hip extensors and knee extensors strength of lower limb in children with spastic diplegic cerebral palsy. Journal of Physical Therapy Science, Vol. 28, Issue 2, 2016, p. 671-676.

[17] Wren T. A., et al. Effect of high-frequency, low-magnitude vibration on bone and muscle in children with cerebral palsy. Journal of Pediatric Orthopaedics, Vol. 30, Issue 7, 2010, p. 732-738.

[18] Tupimai T., et al. Effect of combining passive muscle stretching and whole body vibration on spasticity and physical performance of children and adolescents with cerebral palsy. The Journal of Physical Therapy Science, Vol. 28, Issue 1, 2016, p. 7-13.

[19] Katusic A., Alimovic S., Mejaski-Bosnjak V. The effect of vibration therapy on spasticity and motor function in children with cerebral palsy: a randomized controlled trial. NeuroRehabilitation, Vol. 32, Issue 1, 2013, p. 1-8.

[20] Yabumoto T., et al. Whole-body vibration training improves the walking ability of a moderately impaired child with cerebral palsy: a case study. Journal of Physical Therapy Science, Vol. 27, Issue 9, 2015, p. 3023-3025. 


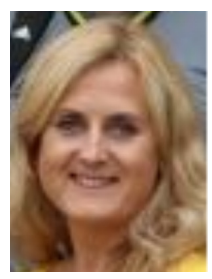

Vilma Dudoniene received her Doctoral degree in biomedical sciences at Lithuanian Sports University in 2000 with the thesis "Effect of heating and exercises on muscle function". Her current position is Associate Professor at Lithuanian Sports University, research interest - effect of different physiotherapy methods on person's functioning.

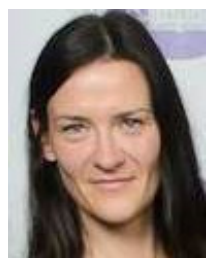

Eglè Lendraitienė received her Doctor's degree in biomedicine at the Lithuanian University of Health Sciences, Kaunas, Lithuania, in 2007. She is currently working at the Lithuanian University of Health Sciences. Her current research interests neurological physiotherapy, different technics and efficiency.

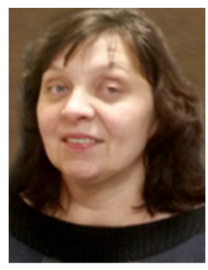

Jurate Pozeriene has defended her doctoral thesis and received Ph.D. in social sciences at Lithuanian Sports University (LSU) in 2002. Her current position is Associate Professor, head of the department of Applied Biology and Rehabilitation at LSU. Recently the research interest is physical, psychological and social rehabilitation of the disabled as well as effect of modern IT technologies in physiotherapy. 